\title{
Library classifications criticisms: universality, poststructuralism and ethics
}

\author{
Daniel Martínez Avila (1), José Augusto Chaves Guimarães (2)
}

(1) Universidad Carlos III de Madrid, España, dmartinezavila@gmail.com

(2) Universidade Estadual Paulista, Marilia, SP, Brasil, guima@marilia.unesp.br

\begin{abstract}
Resumen
Se estudian las críticas a las clasificaciones bibliotecarias desde un punto de vista postestructuralista y pragmatista que se opone al ideal de universalidad en los sistemas de organización del conocimiento. Desde esta perspectiva se hace una revisión de los textos seminales de uno de los autores pioneros en estudios críticos sobre clasificaciones bibliotecarias y se concluye que pese a la búsqueda de neutralidad que impregna algunos de los estudios críticos, éste se trata de un imposible a la vez que contradictorio en la representación de diferentes culturas. El compromiso con el propósito del sistema y la reivindicación de los sesgos se convierten por lo tanto en unos de los principales mecanismos para una ética transcultural en organización y representación del conocimiento.
\end{abstract}

Palabras clave: Clasificaciones bibliográficas. Universalidad. Sesgos. Ética. Organización y representación del conocimiento. Postestructuralismo. Pragmatismo.

\section{Introduction}

One of the major achievements of the knowledge organization community, in terms of the ethical issues in organizing and representing knowledge refers to the criticism of the so-called universal approach of traditional classifications and the 19th century Positivist view of the world.

Authors such as Beghtol (2002, 2005), García Gutiérrez (2002) and Olson $(2002, \ldots)$ among others point out the need of having knowledge organization systems that are able to represent multi and inter-cultural environments in a dialogical perspective.

In this sense, this paper aims to present and discuss the theoretical criticism to "universal" classification systems, mainly focusing on enumerative library classification systems, from a post structuralist approach as a starting point for further studies about the cultural dimension of knowledge organization systems.

\begin{abstract}
We study library classifications criticisms from a poststructuralist and pragmatist point of view that rejects the idea of universality in knowledge organization systems. From this perspective, we analize the seminal texts on library classifications criticisms and conclude that the seek of neutrality in some of these texts is not only an impossible goal but also a contradiction in the representation of different cultures. Therefore, we suggest the commitment with the goals and the recognition of bias in library classifications as an important device for achieving a transcultural ethics in knowledge organization and representation.
\end{abstract}

Keywords: Library classifications. Universality. Bias. Ethics. Knowledge organization and representation. Poststructuralism. Pragmatism.

\section{Theoretical background of criticism to library classifications}

Nearly since it began, the Dewey Decimal Classification has been the object of criticism from different perspectives. These include, for instance, its validity for public libraries and for the purpose of exchanging scientific information. More sophisticated and technically grounded objections came from Indian mathematician and librarian Shiyali Ramamrita Ranganathan, who, during the first half of the 20th century, thoroughly set out the deficiencies of the DDC, and later contrasted them with his assertedly more advanced Colon Classification (Ranganathan, 1967, 1989, among others). However, from a critical perspective, it was not until the 1970s that the reality of this and other library classifications as social, and probably inadequate, constructions was highlighted.

It was in 1971 when A. C. Foskett (1971, p. $117)$, in his seminal work Misogynists All: a Study in Critical Classification stated: 
Classification theorists have always emphasized the importance of the objective approach in the construction of classification schemes; the scheme should not reflect the prejudices of its maker, but should represent some kind of eternal and external truth. However, when one begins to examine almost any scheme it quickly becomes clear that, far from being objective, it is likely to reflect both the prejudices of its time and those of its author.

This was a starting point for the criticism of library classification schemes since before Foskett only subject headings, strikingly with the work of Sanford Berman (1971) had been the object of some critical analysis.

This first work was followed by more than forty years of studies and analyses of the mainstream English language classification systems (i. e. the LCC, the UDC and the DDC), including a 1984 follow-up of Foskett's work entitled "Better Dead Than Read: Further Studies in Critical Classification" (Foskett, 1984). In this follow-up (Bull \& Roberts, 1980, p. 139), Foskett included citations to controversial statements such as

Each new edition of the Dewey Decimal Classification (DDC) is a reproach to the professionalism of libraries. Each new edition adopted by librarians and bibliographers emphasized the disregard that has overtaken classification as a professional technique.

Some of the research that followed Misogynists All monitored and extended Foskett's findings from a particular stance, such as the total absence of the African independent churches in the DDC, LCC and UDC (Afolabi, 1992), and the inadequacy of the DDC for Melanesia (McConnell, 1984, 1985a, 1985b).

Other researchers went a step further in their criticism by holding a poststructuralist stance which Foskett arguably did not have. They did not believe in universal truths and recognized that revising the schemes in a traditional way would only cause new problems of a different nature. In this vein, Hope Olson may be regarded as one of the most active and prominent poststructuralist researchers in the area of Information Organization. Important works by this author that study terminological and structural problems in library organization systems include Thinking Professionals: Teaching Critical Cataloguing (Olson, 1997), Ghettoes and Diaspora in Classification: Communicating Across the Limits (Olson \& Ward, 1997), Mapping Beyond Dewey's Boundaries: Constructing Classificatory Space for Marginalized Knowledge Domains (Olson, 1998), Difference, Culture and Change: The Untapped Potential of LCSH (Olson, 2000), Sameness and Difference: a Cultural Foundation of Classification (Olson, 2001a), her mag- num opus The Power to Name: Locating the Limits of Subject Representation in Libraries (Olson, 2002), and How We Construct Subjects: a Feminist Analysis (Olso,n 2007).

After most of these varied revisions, the DDC editorial team in collaboration with the committees involved in the revision process, the Library of Congress, the UDC editorial team with Extensions \& Corrections and any other discourse of cultural authority involved in the development of standards, using analogies to Olson's third discourse of authority in relation to the LCSH (OIson 2000 , p. 55), appear to have included some of the new suggestions to the universal schemes. The result has been the construction and repair of an opulent "Tower of Babel", full of good intentions and contradictory effectiveness. While most of the problems detected by Foskett have been patched up, the real issue remains untouched. Behind the underlying assumption of universality in knowledge organization in those discourses of authority there is nothing more than the presupposition of universal solutions. Some of these ideas will be discussed below.

\section{The universalist stance of A. C. Foskett seminal criticism to the library classifications}

From a critical perspective, Foskett's famous statement on library classifications reflecting the prejudices of their time and their authors is one with which few people who know and use these systems could disagree. In addition, it would not be very daring to say that the culture and people of their time reflect these library classification prejudices too. Library schemes both reflect and create opinion at the same time; they as tools, and we as professionals and researchers working with information organization shape reality.

It is well known that a very effective way to eradicate a certain group or a people from History is by in no way naming it. An effective way to defame a thing and put an end to its aspirations is to change its meaning to the worst possible one or place it in the wrong context. An effective way to ridicule and isolate someone is by pointing her/him out as abnormal (deviating from the norm) and to exile him/her away from the peaceful and anonymous norm (standard). Foskett proved that library schemes were doing all these things to women, children, LGBT and many other groups outside the mainstream. And, most probably, all these biases were introduced with the unconscious or intentional purpose of reinforcing the power discourses and the status quo. 
One of the main points that can be seen in Foskett's work is that he clearly envisions what he, and likely almost every other critical researcher, considers problematic according to what is today's well accepted politically correct speech. In this vein, he also persistently tries to resolve those problems with universal solutions driven by his good intentions and those values he considered right. Throughout the texts, Foskett satirizes and jokes about his findings, exposing them as something so self evident to us that it seems that the best criticism of the systems comes from within.

However, it may also be argued that Foskett sometimes seems to lack the understanding that the mainstream and politically incorrect view is reflected in the systems not because they are defective, but because that is the way the majority thinks. This seems clearer when he agrees with Sanford Berman stating that (Foskett, 1971, p. 121)

Sanford Berman has pointed out that the Library of Congress Subject Headings represent a white racist imperialist point of view which can prove embarrassing in an African university library. It is more difficult to see exactly what can be done to improve the situation generally. In some cases it would be possible to alter definitions to bring the overall sense more into line with modern ideas.

Along this line, the point is not to prove that the LCSH is embarrassing in an African university library setting, which is frankly easy to do and simple to understand. The real problem is how many users find the LCSH embarrassing in a US university library, for instance? The answer is most likely not the majority, since the standard developed by the Library of Congress reflects the vision of this majority, the mainstream opinion, in an effort 'to disturb the fewest people possible' while accepting that there will inevitably be some victims. Therefore the real problem here seems to be: what happens with all those minorities that are being disturbed?

Another post-structuralist interpretation might be that Foskett's universalist thesis is also built on his attitude toward solutions. Foskett does not offer any solution perhaps because he studies the schemes from many different points of view, as many as different prejudiced groups in the systems, but does not lose his universal vision, and the contradiction seems to confuse him. In Misogynist $A / l$ his final words include the statement: "notational problems make it remarkably difficult to change the existing structure for a more satisfactory one" (Foskett 1971, p. 121). One interpretation of this might be that his words underscore a fear of totally subverting the schemes to make them appropriate for one of those groups being offended since, from a universalist point of view, Foskett might fear that his revision could be inadequate for another group. However, another plausible interpretation of his words might be that Foskett, as an experienced librarian, knew that a complete rearrangement of facets according to the convenience of any of those groups would mean not only a problem for interoperability but also a huge task for libraries in terms of re-classification and costs of changing classmarks and shelfmarks, what in the end might lead to the abandon of the system.

Whether the final goal of Foskett's analyses was to highlight the difficulty of practical solutions or just a wake up call for classificationists and conscious librarians, it might also be argued that Foskett failed to recognize that his judgment on the matter was also following an internal bias of his own caused by society, circumstances, values, education, and so on as well. In other words, confusing bias with prejudices (a word for negative bias according to his own goals and values), and positive bias with "some kind of eternal and external truth", Foskett failed to give a proper explanation for or solution to the problem he had revealed other than a universalist one: the revision of the schemes according to an eternal, non-discriminatory, non-sexist, nonracist, non-offensive, tolerant point of view according to external and politically correct consensus.

And that is what Foskett did in his work: revise several schemes according to a consensus on critical views with the aspiration of a global and universal correction followed by a change of the dominant consensus driving classification development and revision principles. But, as Antonio García Gutiérrez pointed out, consensus in classification must only be provided if there are universal reasons to make it possible, and universality does not always seem to be justified. In this vein, García Gutiérrez also pointed out that a Habermasian consensus, rooted in general agreement, could be referred to, as indeed it was by authors such as Sloterdijk, as totalitarianism, and that overriding will to unify what should be kept diverse at all costs leads to belief in the threat of a single mindset camouflaged in good intentions (García Gutiérrez, 2007, p. 44).

\section{Is there any "light at the end of the tunnel"?}

Considering the questions presented and discussed above, it is possible to state that, from, or perhaps despite, a critical point of view, Foskett failed to recognize rather than reject, that every classification system should be considered a 
reflection of the goals, purposes, values, and consequences of its author and environment even if it does not fit in with our own.

This means that, although library classifications can be regarded as biased, the search of neutrality in classification should also be rejected as an impossible and dangerous, although at times beautiful, ideal concealing the scheme's true intentions (not only negative, but also in terms of intended usefulness). A racist, monotheist or homophobic system would not be more biased than a feminist, multicultural or gay-friendly system, since both of them respond to a given set of values, goals and voices.

Every system is intended for a specific group of users and will technically work better for them, while at the same time it could well be socially controversial or even offensive to other groups. Therefore, the problem with some systems is not necessarily their specific bias or goals, but the prescriptive intention of neutrality and universality in the pursuit of a "better" retrieval process. Birger Hjørland expressed this idea as follows (Hjørland, 2007, p. 8):

Any controlled vocabulary represents a 'prescriptive' or 'normative' knowledge organizing systems. The dominating theory within library and information science have been that such normative vocabularies represent 'neutral, ' 'objective' solutions that simply provide more efficient information systems. We may term this view a 'positivist view' and contrast it with a 'pragmatic view' according to which any controlled vocabulary tends to favour some kinds of queries, while relatively making other kinds of queries more difficult to answer.

Therefore, if we accept that bias in classification will exist, no system can be regarded as universally "better" or "worse" than any other; all of them will be equally good or bad for different purposes (that might be regarded as absurd or even harmful for some communities) with the only difference being that of the favored group and the similarity of their inadequacy for the whole population.

Here, it might be argued that since feminism is not the opposite of sexism (understanding feminism to be the absence of discrimination against women, not discrimination against men) both kinds of systems would not hold an equivalent bias, much the same as David Ingram argues that "affirming 'black pride' is not equivalent to affirming 'white pride, ' since the former - unlike the latter - is a defensive strategy aimed at rectifying a negative stereotype" (Ingram 2004, p. 55). In other words, some biases are considered worse than others, according to certain ethical, legal or religious judgments, since some of them are less "correct" than others.
Concerning ethics, which is probably the most plural and least dogmatic of the three positions, García Gutiérrez claimed that following a "transcultural ethics of mediation" (2002) or, furthermore, an "epistemology of paraconsistency, " the ethical barrier is something that should be broken for the good of theoretical perception through "claiming bad faith as a cultural part of epistemology. Claiming bad faith, obviously, not in the sense of exercising it, but rather to the contrary, by creating mechanisms of explicitation and condemnation in acts of cognition" (García Gutiérrez, 2007, p. 30). Thereby, in the same way that rejecting bias is not the same as recognizing it, rejecting neutrality or recognizing bias is not the same as accepting it. From a pragmatic point of view, every kind of classification should be considered equally biased inasmuch as they all follow a purpose, the reinforcement of discrimination or the end of discrimination, and they all follow different approaches that, luckily or sadly, without judgment, are not unanimously followed so thus cannot be considered neutral.

It is at this point where some researchers, such as Hope Olson and others (1998, 2001b, 2001a, 2002, 2007; Kublik et al., 2003; Feinberg, 2007), have stepped forward and overcome the problem by offering solutions while superseding universality and adopting a critical and pragmatic point of view. Along this line, Olson described the problem of universality in Dewey as follows (Olson, 2002, p. 18):

Dewey bases his scheme on the unquestioned presumption that universality is not only desirable, but necessary. This universality is characterized by a focus on sameness - privileging it over difference and diversity. To achieve universality, Dewey creates the structure of DDC as a universal language. This content and structure defines an epistemic canon by including and prioritizing areas of knowledge relative to each other. To fulfill the potential of this system, Dewey prescribes consistency in the application of DDC as a requirement.

\section{Conclusions}

Therefore, to overcome the problem of universality in library classifications, the solution cannot be universal. If the solution required a total restructuring of hierarchy, Foskett saw this as a difficulty. He might tend to adopt some particular stances but, on the whole, he just set out the inviability of a universal solution and his resignation to not providing, from a critical, or perhaps politically correct, point of view, a universal solution.

Pragmatism in Knowledge Organization should not be considered a consequence of a political 
stance but an assumption inherent to every possible political stance in an unavoidable situation of no consensus, or as previously expressed following Sloterdijk's comment on Habermas, an even desirable situation of efforts to avoid totalitarianism. If there are several possibilities for developing/arranging a classification, each one will be linked to a goal independent of the ideology behind the point of view that creates the system, although every goal might reciprocally be considered part of an ideology. This is not a rejection of neutrality; it is simply acceptance of its inexistence. This is a vindication of deliberate militancy in classification as an act of honesty, a militancy that may be an object of praise or criticism, and which might not always be in accordance with the "established" views. As Hjørland pointed out, Pragmatism should not be considered a part of only alternative points of views but as something inherent in a point of view itself (Hjørland 2009, p. 1526):

Examples [of pragmatism] may be classifications developed on the basis of feminist theory (i. e., knowledge organizing systems developed to support a stated goal such as women's liberation). Pragmatism is not, however, limited to leftish, feminist, or other 'alternative' points of view. Although it seems to be, on the face of it, opposed to basic scientific ideals of searching truth (rather than to politicize), pragmatism is based on the assumption that knowledge cannot be neutral (because of its teleological nature) and, therefore, it is important to uncover the inherent values and consequences in any knowledge claim, in any conception, and in any classification.

From our pragmatic point of view, the solution to the whole problem of universalism in library classification systems would be the development of local classification systems and special schemes in which the system's unique perspective and intended users are clearly identified. This solution would prevent unethical impositions of unavoidably biased systems to wrong audiences.

However, provided that one of the immediate purposes of library classifications is to serve as a standard for data interoperability across bibliographical records, databases, etc., it is somehow ironic that some questions posed in this paper were partially addressed by A. C. Foskett's own brother, D. J. Foskett, when he advocated for a "ur-classification" (Foskett, 1974, 1991) that, as a type of universal language, would establish common concepts and enable translations between different special schemes.

However, we also agree with Melanie Feinberg (2007) when she points out the problems of this universal solution in contrast to the ackno- wledgment of the existence of multiple and perhaps contradictory domains:

The approach of the ur-classification or language of perspicuous contrast relies on the identification of common concepts that are consistently related and are universally applicable. If concepts need to be redefined entirely from one context to another, or if they just don't apply at all in different contexts, then there is no way to perform the translation (the concepts are incommensurable).

In conclusion, and if we accept that neutrality does not exist and the deliberate militancy in classification can be considered not only an act of honesty but also an object of praise or criticism, the ethical commitments become not only possible but, as a matter of fact, necessary in a growing multicultural and interconnected world where the differences are not the exceptions anymore, but, perhaps, the new "norm".

\section{References}

Afolabi, Michael (1992). Spiritual Matters: Provision for Independent African Churches in General Classification Schemes. // International Classification. 19:4, 210-213.

Beghtol, Claire (2002). A proposed ethical warrant for global knowledge representation and organization systems. // Journal of Documentation. 58:5, 507-532.

Beghtol, Claire (2005). Ethical decision-making for knowledge representation and organization systems for global use. // Journal of the American Society for Information Science and Technology. 56:9, 903-912.

Berman, Sanford (1971). Prejudices and antipathies: a tract of Library of Congress Subjects Headings concerning people. Metuchen, N. J.: Scarecrow Press, 1971.

Bull, G; Roberts, N (1980). Review of Dewey Decimal Classification and Relative Index, 19th ed. // Journal of Librarianship. (12 April) 139.

Feinberg, Melanie (2007). Hidden bias to responsible bias: an approach to information systems based on Haraway's situated knowledges. // Information Research. 12:4, paper colis07. http://informationr.net/ir/12-4/colis07.html (2013-04-27).

Foskett, Anthony Charles (1971). Misogynists All: A Study in Critical Classification. // Library Resources \& Technical Services. 15:2 (Spring) 117-121.

Foskett, Douglas John (1974). Classification and indexing in the social sciences. (2nd ed.). London: Butterworths.

Foskett, Anthony Charles (1984). Better Dead Than Read: Further Studies in Critical Classification. // Library Resources \& Technical Services. 28 (November/December) 347-359.

Foskett, Douglas John (1991). Concerning general and special classifications. // International Classification. 18:2, 87-91.

García Gutiérrez, Antonio (2002). Knowledge organization from a "culture of the border": towards a transcultural ethics of mediation. // López-Huertas, María José (ed.). Challenges in knowledge representation and organization for the 21st century. Integration of knowledge across boundaries. Advances in Knowledge Organization 8. Würzburg: Ergon-Verlag, 2002. 516-522.

García Gutiérrez, Antonio (2007). Desclasificados: Pluralismo Lógico y Violencia de la Clasificación. Rubí, Barcelona: Anthropos, 2007. 
Hjørland, Birger (2007). Arguments for 'The Bibliographical Paradigm. ' Some Thoughts Inspired by the New English Edition of the UDC. // Information Research 12: 4 paper colis06. http://InformationR.net/ir/12-4/colis06.html (2013-04-27).

Hjørland, Birger (2009). Concept Theory. // Journal of the American Society for Information Science and Technology. 60:8, 1519-1536.

Ingram, David (2004). Rights, Democracy, and Fulfillment in the Era of Identity Politics: Principled Compromises in a Compromised World. Lanham, MD: Rowman \& Littlefield, 2004.

Kublik, Angela; Clevette, Virginia; Ward, Dennis; Olson, Hope A. (2003). Adapting Dominant Classifications to Particular Contexts. // Cataloging \& Classification Quarterly. 37:1/2, 13-31.

McConnell, Fraiser (1985a). Languages of Melanesia: Problems and Proposals for Classification. // Cataloging \& Classification Quarterly. 5:3, 57-66.

McConnell, Fraiser (1985b). Peoples of Melanesia: Proposals for Revision of DDC19. Table 5. // Cataloging \& Classification Quarterly. 5:4, 47-51.

Olson, Hope A. (1997). Thinking Professionals: Teaching Critical Cataloging. // Technical Services Quarterly. 15:1/2, 51-66.

Olson, Hope A. (1998). Mapping Beyond Dewey's Boundaries: Constructing Classificatory Space for Marginalized Knowledge Domains. // Library Trends. 47:2 (Fall) 233251.

Olson, Hope A. (2000). Difference, Culture and Change: The Untapped Potential of LCSH. // Cataloging \& Classification Quarterly. 29:1/2 53-71.
Olson, Hope A. (2001a). Sameness and Difference: a Cultural Foundation of Classification. // Library Resources \& Technical Services. 45:3, 115-122.

Olson, Hope A. (2001b). The Power to Name: Representation in Library Catalogs. // Signs: Journal of Women in Culture and Society. 26:3, 639-668.

Olson, Hope A. (2002). The Power to Name: Locating the Limits of Subject Representation in Libraries. Dordrecht, Netherlands: Kluwer Academic, 2002.

Olson, Hope A. (2007). How We Construct Subjects: A Feminist Analysis. // Library Trends. 56:2 (Fall) 509-541.

Olson, Hope A.; Ward, Dennis B. (1997). Ghettoes and Diaspora in Classification: Communicating Across the Limits. // Frohmann, Bernd (ed.). Communication and Information in Context: Society, Technology, and the Professions. Proceedings of the 25th Annual Conference/Association canadienne des sciences de l'information: Travaux du 25e congrès annuel. Toronto, Ontario: Canadian Association for Information Science, 1997. 19-31.

Ranganathan, Shiyali Ramamrita (1967). Prolegomena to library Classification. Assisted by M. A. Gopinath 3rd edition. Asia Publishing House, 1967.

Ranganathan, Shiyali Ramamrita (1989). Philosophy of Library Classification. Bangalore: Sarada Ranganathan Endowment for Library Science, 1989.

Enviado: 2013-06-05. Segunda versión: 2013-06-30 Aceptado: 2013-08-17. 